\title{
Secondary school admissions in England 2001 to 2008: Changing legislation, policy and practice
}

\begin{abstract}
The distribution of pupils amongst schools is fundamental to concerns about equality of educational opportunity and it is for this reason that the process by which pupils are admitted to schools is of significance. This paper focuses on admissions criteria and practices used by English secondary schools in 2001 and 2008 in light of changes to legislation and the regulatory context. In 2008, unlike 2001, virtually all schools gave priority to children in care and very few used interviews. In a minority of schools, predominantly those responsible for their own admissions, criteria designed to 'select in' certain pupils were used, with partial selection by aptitude/ability increasing over time. An analysis of 'supplementary information forms' revealed that a minority of schools requested information that was prohibited and unrelated to admissions criteria. Notwithstanding some positive impacts, further changes could make the admissions process easier for parents/carers and enhance equality of educational opportunity.
\end{abstract}

\section{Introduction}

Issues surrounding school admissions and the ways in which pupils are distributed amongst schools are fundamental to concerns about equality of educational opportunity. Under the Labour government, elected into office in 1997, there were major changes to school admissions in England. This paper assesses how legislative and quasi-legislative instruments have been associated with changes to admissions criteria and practices adopted by publicly-funded secondary schools (excluding academically selective grammar schools) between 2001 and 2008.

The key question that we seek to address is how have secondary school admissions criteria and practices changed? In particular, to what extent have those relating to equality, social justice and school selectivity changed? Drawing on two large-scale surveys, we explore variation over time and between schools of different types. We argue that although there is now less scope for schools to socially select pupils, there is considerable scope for overt selection by aptitude which is permitted by legislation: thus, whilst some of the changes that have taken place have improved access to secondary schools for certain groups of disadvantaged pupils, others are likely to have improved access for more advantaged pupils. Moreover, the admissions process is complex and further policy changes would seem to be desirable to enhance equality of educational opportunity. The following section provides an overview of the historical context and this is followed by an examination of the legislative and policy context. Previous research on school admissions is reviewed before admissions criteria in place in English (non-grammar) secondary schools in 2001 
and 2008 are examined. The final section discusses the main findings and their implications for equality of educational opportunity, policy and practice.

\section{$2 \quad$ Historical context}

The historical and political context is fundamental to any discussion of school admissions in England. The 1944 Education Act aimed to increase educational opportunity and allowed for the implementation of a 'tripartite' system of secondary education, with grammar schools for the most academically able, technical schools and secondary modern schools. ${ }^{1}$ Admission was based, in the main, on the results of the 'eleven-plus', a test of ability taken in the final year of primary school. Major concerns relating to equality of opportunity were, however, raised (Chitty, 2004), a key one being that the main beneficiaries of grammar schools were the middle classes (Floud et al., 1956; Simon, 1991). Following the election of the Labour government in 1964, local education authorities were requested in 1965 to submit plans for the introduction of comprehensive education. Although this request was withdrawn following the election of a Conservative government in 1970 (Simon, 1991), proposals for comprehensive reorganisation continued to be submitted and by the early 1980s comprehensive education was almost universal (Gordon et al., 1991), although grammar schools were retained by some local authorities. ${ }^{2}$

Significant changes took place under successive Conservative administrations between 1979 and 1997; these were heavily influenced by the neo-liberal ideas of the 'New Right' (Chitty, 2004). The 1980 Education Act gave an increased emphasis to parental choice of school and this was followed by the 1988 Education Reform Act. A combination of parental 'choice', funding schools predominantly on the basis of pupil numbers, the requirement for schools to admit pupils to their physical capacity, and the publication of public examination results via 'league tables' created a 'quasi-market' (Le Grand and Bartlett, 1993), with schools being incentivised to increase the number of pupils admitted and maximise their 'league table' position. Schools could also opt out of local authority control and become grant-maintained, so gaining control over admissions from the local authority and joining those schools that had long had this responsibility, namely voluntaryaided schools (most under the control of the churches).

Concerns were expressed about the administration of school admissions. Some of these related to voluntary-aided secondary schools. A report reviewing primary education in inner London (ILEA, 1985) examined the banding process which sought to achieve an academically balanced intake across secondary schools in the authority (see West, 2005) and noted that there was evidence that some voluntary-aided secondary schools took a disproportionate number of higher ability pupils or 
obtained an intake with higher than average achievement levels. The report noted that suspicions about the actions of such schools 'could only be allayed' if all voluntary schools used the same procedures as schools under the control of the local authority and specifically 'abandoned the practice of interviewing pupils before allocation' (ILEA, 1985, p. 58).

Following the 1988 Education Reform Act, others also expressed concerns about the admissions process (e.g., Audit Commission, 1996), the use of interviews, overt selection on the basis of ability or aptitude, social or covert selection and complex application procedures (Gewirtz et al., 1995; West et al. 1998). Certain practices identified appeared to privilege some children over others, thus raising concerns about equality of educational opportunity.

\section{Legislative and policy context}

In its 1997 manifesto, the Labour Party committed itself to open and fair guidelines for admissions (Labour Party, 1997). The 1998 School Standards and Framework Act subsequently established a new legal framework for admissions. Two key mechanisms were introduced: a Code of Practice on School Admissions and the Office of the Schools Adjudicator. Schools Adjudicators have a specific role in determining objections to admission arrangements. They are independent of government and decisions they make are binding on all the parties involved and can only be challenged through judicial review. Disputes about admissions criteria relating to religious issues are taken by the Secretary of State for Children, Schools and Families (the most senior government minister), not by Adjudicators (Department for Education and Employment (DfEE), 1999; Department for Education and Skills (DfES), 2003, 2007).

Parents/carers must be allowed to express a minimum of three 'choices', or more accurately 'preferences' for publicly-funded secondary schools for their child, generally at the age of 11 years when they move from primary to secondary school (see DfES, 2007). They are required to complete a 'common application form' which is provided by and returned to their local authority. In some cases schools are permitted to seek additional information about prospective pupils, by asking parents/carers to complete supplementary information forms (SIFs). If there are fewer applicants than places available at a particular school, all those expressing a preference must be offered a place for their child; ${ }^{3}$ if there are more applicants than places available, the school's published oversubscription criteria are used to determine which children are offered a place. Schools with responsibility for admissions have more room to decide on their admissions criteria than other schools whose admissions policies are set by the local authority. Such schools are in a 
position - if they so wish - to seek to select in and out certain types of pupils via their oversubscription criteria.

Admission authorities (either the local authority or the school, in the case of schools with responsibility for admissions) must comply with the law, but until 2007 they were only required to 'have regard to' the guidance given in the School Admissions Code; having done so, they were able to set admissions criteria that did not comply with the Code as long as they had good reasons for their actions (House of Commons Education and Skills Committee, 2004).

The first Code of Practice came into force on 1 April 1999 (DfEE, 1999) and applied to arrangements leading to admissions from September 2000. In terms of the criteria to be used, the Code noted that admission authorities had 'a fairly wide discretion to determine their own oversubscription criteria provided these criteria are objective, fair, compatible with admissions and equal opportunities legislation' (1999, para. 5.2). It also gave some frequently used criteria considered to be acceptable including 'sibling links, distance from the school, ease of access by public transport, medical or social grounds, catchment areas and transfer from named feeder schools, as well as parents' ranking of preference' (para. 5.3).

The general guidance was broadly similar in the second Code. Criteria were not to be unlawful; the admission authority had to consider the factors it believed to be the most important to ensure that children received an 'efficient and suitable education' and to have had 'had regard to the guidance' in the Code; and the criteria were to be 'clear, fair and objective' and published (DfES, 2003, para. A.51).

Further changes followed the Education and Inspections Act 2006 which prohibits interviews 'where the interview is to be taken into account...in determining whether the applicant is to be admitted to the school' (part 3, s 44). 'Admission authorities must not use either face-to-face interviews or interviews by telephone or other means' (DfES, 2007, 1.46). Concerns about religious segregation in schools with a religious character led to the inclusion in the Education and Inspections Act of a new duty for school governing bodies to 'promote community cohesion' (part 3, section 38). The legislation also requires local authorities to ensure fair access to educational opportunity (part 1, s 1). Finally, the Education (Admission of Looked After Children) (England) Regulations introduced in 2006 require an admission authority to give 'first priority in its oversubscription criteria to all relevant looked after children' (s 3). 
The third School Admissions Code (DfES, 2007) which came into force in February 2007, and applied to admissions from September 2008, differed from the previous Codes in that there were certain provisions that were mandatory and certain practices that were not to be used as shown in Figure 1.

Figure 1 here

Failure to comply with these mandatory provisions means that the body concerned is in breach of its statutory duty to act in accordance with the provisions in the Code. This could result in an objection being made to the Schools Adjudicator or a complaint being made to the Secretary of State for Children, Schools and Families (DfES, 2007). ${ }^{4}$

The following sections focus on three fundamental themes in the School Admissions Codes which cross cut our analysis, namely those relating to equality and social justice and to school selectivity and selection on the basis of faith.

\section{Equality of opportunity and access and social justice}

The first Code of Practice (DfEE, 1999) noted that in light of the Sex Discrimination Act 1975 and the Race Relations Act 1976 'admission authorities should consider the possible impact, direct or indirect, on equal opportunities of their proposed oversubscription criteria' (para 5.7). The second Code (DfES, 2003) reiterated these points and also noted that criteria such as giving preference to children whose siblings had previously attended the school, or with parents in specific occupations, for example teachers, could disadvantage certain individuals who had recently moved into the area. The third Code (DfES, 2007) had a mandatory requirement in relation to what is termed 'fair access', namely:

Admission authorities and governing bodies must ensure that their admission arrangements... are fair and do not disadvantage, either directly or indirectly, a child from a particular social or racial group, or a child with a disability or special educational needs...Admission authorities must also ensure that their admission arrangements comply with all other relevant equalities legislation... (para 1.67).

The Code went further stating that: 
Admission authorities and governing bodies should develop and implement admission arrangements, practices and oversubscription criteria that actively promote equity, and thus go further than simply ensuring that unfair practices and criteria are excluded (para 1.67).

Moreover, random allocation

can be good practice particularly for urban areas and secondary schools...It may be used as the sole means of allocating places or alongside other oversubscription criteria. Random allocation can widen access to schools for those unable to afford to buy houses near to favoured schools and create greater social equity (DfES, 2007, para 2.28).

Reference was also made to pupil ability banding which 'is used by some admission authorities to ensure that their intake includes a proportionate spread of children of different abilities' (DfES, 2007, para 2.79). Banding is of different types: some is in relation to individual schools, some in relation to two or more schools and some across a local authority area (DfES, 2007; West, 2006). School-level systems of banding amongst all applicants meeting the required criteria provide schools with strong incentives to ensure that the pool of applicants amongst which they administer the banding is high attaining (on average) (Allen and West, 2009).

The second Code of Practice (DfES, 2003) made explicit reference to 'looked after' children, a particularly disadvantaged group. A looked after child is one who is in the care of a local authority or provided with accommodation by that authority. The Code recommended that admission authorities give looked after children 'top priority' in their oversubscription criteria (para. 7.22). The third Code (DfES, 2007) stated that, in line with regulations 'All admission authorities must give highest priority in their oversubscription criteria to these children' (para 2.7).

All Codes have addressed the admission of children with statements of special educational needs; this is underpinned by the Education Act 1996 and as stated in the third School Admissions Code (DfES, 2007), this 'requires the governing bodies of all maintained schools to admit a child with a statement of special educational needs that names their school' (para 1.50). 'This is not an oversubscription criterion; schools must admit such children whether they have places or not' (DfES, 2007, para 2.6). The key point to bear in mind is that the admission of children with statements of special educational needs is carried out differently from the admission of other children. 


\section{Selection by aptitude and ability}

The 1998 Schools Standards and Framework Act ruled out the introduction of any new selection on the basis of academic ability; however, existing selection by aptitude or ability was allowed to continue if in place during the 1997/98 school year. New selection on the basis of aptitude in a prescribed subject is allowed in limited circumstances where the school has a specialism (this includes specialist schools) and where the proportion selected is no more than $10 \%$ of the school's intake. The relevant subjects from 31 December 2008 were modern foreign languages, the performing arts, visual arts and physical education or sport; design and technology and information technology (School Admissions (Admission Arrangements) (England) Regulations, 2008). ${ }^{5}$

The 1998 School Standards and Framework Act defines 'ability' as 'either general ability or ability in any particular subject or subjects' (Chapter II, 99, 5 (b)). It does not define aptitude, but the School Admissions Code states that a child with aptitude is one who 'is identified as being able to benefit from teaching in a specific subject, or who demonstrates a particular capacity to succeed in that subject' (DfES, 2007, para 2.75).

\section{Access to religious schools}

The second Code of Practice stated that faith schools can make a contribution 'to community cohesion by having admission arrangements that are inclusive of other faiths and of all elements of the population of their local area' (DfES, 2003, para. 3.10). The guidance in the 2007 Code (DfES, 2007) was stronger, stating that governing bodies of all maintained schools 'must promote community cohesion' making reference to the Education and Inspections Act 2006, and noting that the school inspection body Ofsted 'will report on the discharge of this duty' (para 1.13). One way schools with a religious character might do this is via prioritising children from other faiths or of no faith.

\section{Previous research}

Several studies have examined admissions criteria and practices across different types of secondary schools in England (e.g., Coldron et al., 2008; West et al., 2004; Pennell et al., 2006). Research relating to admissions in 2001 found that a significant minority of secondary schools, in the main those that are responsible for their own admissions, used a variety of criteria that appeared to be designed to select in certain groups of pupils: these included giving priority to the children of employees; those of former pupils; those with a family connection to the school; and selecting a proportion of children on the basis of aptitude/ability in a subject area(s) (West et al., 2004). 
Subsequent research examined changes between 2001 and 2005 in London (Pennell et al., 2006; West, Pennell and Hind, 2009). The most marked change was in the increased proportion of secondary schools prioritising children in care. There was also an increase in the percentage of schools selecting a proportion of children on the basis of aptitude/ability in a subject. However, there was a decrease in the use of other potentially selective/discriminatory admissions criteria. The study also examined supplementary information forms used by certain schools, finding that in some cases parents/carers were asked to provide information relating to personal circumstances that appeared unrelated to the school's admissions criteria. Principal-agent theory can be used heuristically to explain the differing responses of schools of different types (West, Pennell and Hind, 2009): whilst local authorities act broadly in line with government guidance and regulations as the agent of the government, schools (voluntary aided and foundation) with responsibility for admissions and acting as agents do not necessarily do so. This, it can be argued, is because the regulatory mechanisms had been insufficient to motivate them to act as intended in the light of the other policy goals and incentives accompanying the market-oriented reforms, notably, maintaining or raising the school's position in the examination league tables.

Coldron et al. (2008) found that although admissions were better regulated in 2006 than in 2001, some schools responsible for admissions, in particular voluntary aided schools, were less compliant with the second Code (DfES, 2003) and were more likely to select covertly than community schools. They also found that there had been an increase (from less than $1 \%$ to $4 \%$ ) in the proportion of schools selecting $10 \%$ of their intake on the basis of aptitude. Voluntary aided and foundation schools were more likely to select in this way than community or voluntary controlled schools. They also investigated the use of supplementary information forms required by schools finding that around one in three non-community schools asked for additional information with voluntary aided schools being more likely to do so than any other school type.

An investigation of the admission arrangements of 570 schools in three local authorities to assess their compliance with the School Admissions Code and associated legislation was also carried out (DCSF, 2008b). Responses from 106 schools found that 96 had arrangements that did not comply with statutory requirements. The most common type of non-compliance was failing to give top priority to looked after children. Other non-compliance related to schools requesting information prohibited by the Code on supplementary information forms. A disproportionate number of schools with non-compliant arrangements were responsible for their own admissions. 
In 2008, the Schools Adjudicator was asked to review the compliance of admission arrangements with the School Admissions Code. Around 3000 of the 5300 foundation and voluntary aided schools in England were selected and their arrangements checked by lawyers. Problems were found with a high proportion: in over 800 schools major contraventions were identified. These included failing to give top priority to children in care; giving priority to siblings not currently at the school; and using unclear oversubscription criteria. These were reported to be due to 'misunderstanding of the Code and related statutes' (Office of the Schools Adjudicator, 2008, para 5).

\section{$5 \quad$ Admissions criteria and practices}

This section of the paper focuses on secondary school admissions criteria and practices for admission in Year 7 (age 11 to 12 years) in September 2001 and September 2008. We focus on non-grammar secondary schools only. The methods adopted and key findings follow.

\section{Methods}

The research involved setting up two databases of admissions criteria to individual publicly-funded secondary (or high) schools in September 2001 and 2008. ${ }^{6}$ For 2001, data were collated for the vast majority (95\%) of secondary schools in England ( $\mathrm{N}=3013)$; 15 city technology colleges, officially classified as 'independent' were excluded. Data were obtained from local authority (LA) brochures and from individual admission authorities (voluntary-aided and foundation schools) where information was not provided in brochures. The missing schools were foundation/voluntary-aided schools that were not included in brochures and did not provide information when asked for details (West et al., 2004).

Data on admissions criteria and practices for publicly-funded secondary schools for September 2008 were obtained from information provided by the 150 LAs in England with publicly-funded secondary schools (excluding the Isles of Scilly). ${ }^{7}$ Although LAs had a statutory responsibility to publish these, in some cases inadequate information was provided about schools responsible for their own admissions (voluntary aided, foundation and academies) so individual schools were contacted. A total of 3134 secondary schools were included in the sample, virtually all those in England. ${ }^{8}$ Academies and city technology colleges were included given that the former are required to adhere to certain aspects of legislation and guidance (see also West, Barham and Hind, 2009).

For 2008 only, an analysis of supplementary information forms (SIFs) was carried out. Schools utilising SIFs were identified via details of the application procedure made available for parents/carers (see West, Barham and Hind, 2009 for details). 479 non-grammar secondary schools with one or more SIFs were identified. A total of 182 forms were obtained, a notional response rate 
of $38 \%$. Given that the sample was neither representative nor random, the results of the analysis cannot be taken as applicable for the entire population of schools using SIFs, but they are likely to give a reasonable indication of practice amongst the schools that use them.

\section{Admissions criteria}

This section highlights key features to emerge from our analysis of admissions criteria and other policies and practices. Table 1 gives the main admissions criteria used.

\section{Table 1 here}

Highly significant changes took place between 2001 and 2008, with virtually all schools in 2008 reporting that priority was given to children in care in the event of a school being oversubscribed. Somewhat fewer schools gave priority to children with medical/social need in 2008 and more gave priority to compassionate/exceptional factors, for example:

Children for whom there are exceptional personal/domestic circumstances presented by the parents or carers, which justify, in the Council's view, admission to a particular school (few applications fall within this category) (community schools in one LA).

The percentage of schools giving priority to children with statements of special educational needs increased from $39 \%$ to $53 \%$. As noted earlier, the admissions process for children with statements of SEN is different from that for others. ${ }^{9}$ Other key differences between the 2001 and 2008 were that the percentage of schools selecting a proportion of pupils on the basis of aptitude/ability in a subject area and the percentage using random allocation increased.

We now examine in more detail the admissions criteria and practices used in relation to the key themes outlined: vulnerable children, equality, partial selection by ability/aptitude, and social cohesion.

\section{Children in care}

From 2006, it was a statutory requirement that children in care should be given top priority in the event of a school being oversubscribed. Religious schools 'may give first priority to all children in care, whether of the faith or not, but must give first priority to children in care of their faith above other children of their faith and, where they give any element of priority to children not of their faith, must give priority in their oversubscription criteria to looked after children not of their faith above other children not of their faith' (DfES, 2007, para 2.8). 
In 2008, virtually all schools (99\%) had an admissions criterion relating to children in care compared with $2 \%$ in 2001 . Some schools did not include this criterion and as shown in Table 2, more of these were responsible for their own admissions (voluntary aided (VA), academies/CTCs (A), foundation $(\mathrm{F}))$ than others (community/voluntary controlled (C/VC)).

Table 2 here

In a small proportion of cases (5\%), children in care were given the highest priority in admissions criteria along with other children, notably those with statements of special educational need for whom the school had been named on the statement. In $9 \%$ of schools, in care was not the top criterion as required: this was the case for $17 \%$ of academies/city technology colleges, $10 \%$ of community/voluntary controlled schools, $6 \%$ of foundation schools and 5\% of voluntary aided schools.

\section{Special educational needs}

In 2008, over half (53\%) of the schools' admissions criteria made reference to pupils with statements of special educational needs (SEN) compared with $39 \%$ in 2001 . Fewer foundation and voluntary aided than other school types referred to this group of pupils, with academies followed by community and voluntary controlled schools being more likely than others to do so (see Table 3 ).

Table 3 here

It might be argued that children with special educational needs may be less likely to apply to particular schools because no mention is made of children with statements of SEN in their admissions criteria. Indeed, there is evidence that the proportion of children with statements of SEN is somewhat lower in Church of England and Roman Catholic secondary schools than in schools without a religious character (2.2\% and $1.9 \%$ versus $2.4 \%)$ (HC 2005).

\section{Lottery/random selection}

Given the increase in the number of schools using random selection (from less than $1 \%$ to $6 \%$ ) we explored the types of schools using this method (see Table 4).

Table 4 here 
Six per cent of schools used lotteries/random selection in 2008 compared with less than $1 \%$ in 2001 . A higher percentage of academies used this form of selection than other school types. Altogether lotteries were used in just over a quarter of all LAs (39). In most cases, a lottery was used by only one or two schools in a given LA. However, in eight LAs it was used in the majority of schools, for example as a final tie break in the case of the distance criterion. In a small number of cases random selection was of a different nature: for example, in one academy half the places were offered to 'applicants living within three miles and south of [named river] on the basis of an independently operated random allocation.'

\section{Banding}

Banding was used by the same proportion of schools in both 2001 and 2008 as shown in Table 5.

Table 5 here

It is interesting to note that banding was used by a high percentage of academies. In 2008, it was used by schools in 34 LAs. In five LAs banding was used across the LA (Greenwich, Hackney, Lewisham, Southwark, Tower Hamlets) although not necessarily in every single school. In the remaining LAs, individual schools carried out their own banding. ${ }^{10}$ In 2001, banding was used by schools in fewer LAs (15); in four LAs it was used across the LA (all the above except for Hackney). ${ }^{11}$

\section{Criteria relating to aptitude/ability}

Although it may, in theory, be possible to differentiate demonstrating aptitude from ability, it does not appear to be possible on the basis of the information available about the tests/assessment used (see also Coldron et al., 2009). Moreover, given that some schools referred to 'ability' or achievement in a subject area, we focused on partial selection by either aptitude/ability in particular subject areas. ${ }^{12}$

Overall, we found that in 2008, $5 \%$ of secondary, non-grammar, schools selected a proportion of pupils on the basis of ability/aptitude in one or more specific subjects; this compares with $3 \%$ in 2001. The highest percentage of schools selecting in this way were academies/city technology colleges, followed by foundation and voluntary aided schools (see Table 6).

Table 6 here 
It is thus clear that the schools selecting a proportion of pupils by aptitude/ability were predominantly those that were their own admission authority. Some criteria suggest that the process of identification of 'aptitude' may be subjective and so open to discretion, or based on attainment:

When considering the application of a pupil in [this] category the governors' admission panel will take into consideration written recommendations from creditable organisations, submitted in support of the application. For example: dance school, youth theatre group, Associated Examination Board certificates (voluntary aided specialist).

\section{Religious schools}

Religious criteria were used by nine out of ten voluntary aided schools in both 2001 and 2008. This is unsurprising given that most such schools have a religious character. In 2008, the variation in the number of religious criteria used by schools of different types was examined (see Table 7).

\section{Table 7 here}

The number of religious criteria was very high in some cases: over a fifth of voluntary aided schools had at least four admissions criteria relating to religion and some as many as 11 . In addition, just over one in ten schools (11\%) had criteria within broad categories (for example, open and religious places). More voluntary aided schools than other types of schools used these nested criteria (34\%). This of course adds to the complexity of the admissions process to such schools; as noted in the case of one voluntary-aided school: 'A complex procedure applies when, in any band and any category, there are more applicants than there are places available'.

Amongst voluntary aided schools, $46 \%$ gave priority to those from other denominations, $42 \%$ to those of other faiths and 4\% to those of other faiths or denominations. In 2001, 23\% gave priority to other faiths.

\section{Potential for 'selection'}

\section{Interviews, meetings}

Interviewing prior to the offer of a place was prohibited by the Education and Inspections Act 2006 and by 2008, very few schools were interviewing, although a few held pre-admission 'meetings' with parents. Interviews were most common in voluntary aided schools. In 2001, 11\% reported interviewing parents and in 2008 , this had reduced to less than $1 \%$. Interviews with pupils also 
decreased from $16 \%$ to less than $1 \%$. It is significant, however, that in four schools - two voluntary aided and two foundation schools - supplementary information forms (see below) made reference to interviews. These schools did not report interviewing in the local authority admissions brochure.

\section{Supplementary information forms}

For 2008 only, an analysis of supplementary information forms (SIFs) was undertaken. Of the 182 forms obtained, almost three-quarters related to voluntary aided schools (74\%), just under a fifth to foundation schools (17\%) and the remainder academies and community schools (four were specialist schools and one a school selecting a proportion of pupils on the basis of ability). Thus, it was principally schools with a religious character that utilised SIFs in order to obtain additional information about the religion, religious denomination or practice of prospective pupils/parents/carers. The School Admissions Code (DfES 2007) provided guidance to schools about their use of supplementary information forms as shown in Figure 2.

Figure 2 here

A significant minority of secondary schools asked questions that were either not allowed or sought information of a similar type: 29\% (52 out of 182) asked about parental occupation, marital status, financial status, criminal convictions, whether the child had been excluded, ethnicity, nationality, refugee/asylum status, homelessness status, the applicant's birth place, when the applicant arrived in the UK, parents' hobbies (non-religious), child's hobbies (non-religious and non-specialist), sibling details, whether there was a previous sibling connection to the school or another family connection to the school (e.g. governors, cousins, parents).

Three quarters of schools asked parents/carers or external referees to complete a single form with around a fifth of the remainder (21\%) asking for two forms to be completed. The length of the total number of forms issued by each school ranged from 1 to 16 A4 pages (mean 2.7).

\section{Discussion}

This paper has examined secondary schools' admissions criteria and practices in England between 2001 and 2008 in light of the new legislative and regulatory context following the 2006 Education and Inspections Act and the third School Admissions Code (DfES, 2007). There have been noteworthy changes. In 2008, unlike 2001, virtually all schools gave priority (and in the main top priority) to children in care. More schools mentioned in their admissions criteria children with statements of special educational needs: a higher proportion were community/voluntary controlled 
schools and academies than voluntary aided or foundation schools. Very few schools used interviews which were prohibited by the Education and Inspections Act 2006, although there was some evidence of pre-admission meetings by schools responsible for admissions. Fewer schools in 2008 than 2001 used criteria that could be used for social/covert selection (e.g., giving priority to the children of former pupils/staff). However, more selected pupils on the basis of aptitude/ability in a subject area. The highest proportion of schools that selected in this way (allowed by legislation and guidance) were academies and foundation schools. A larger proportion of schools used random allocation in the event of oversubscription in 2008 than in 2001 and more voluntary aided schools gave priority to children of other faiths.

Supplementary information forms were used by some schools and some requested information not permitted by the School Admissions Code or information unrelated to the school's admissions criteria: these were virtually all voluntary aided or foundation schools as opposed to either academies whose admissions policies are agreed with the Secretary of State, or community/voluntary controlled schools.

The government has been seeking to ensure that its agents - LAs and voluntary aided and foundation schools - behave as intended in terms of their admissions policies and practices (academies' admissions criteria are part of the funding agreement with the Secretary of State, the principal). However individual schools, as admission authorities, may seek to circumvent guidance if they feel that there are opportunities to do so and the incentives are great enough. It is significant that schools have become more responsive to guidance and moved from covert to overt forms of selection, with more schools selecting a proportion of pupils on the basis of aptitude in a subject area than was the case previously. In short, the legislative reforms appear to have had an impact on schools' published admissions criteria and practices but where there are opportunities for schools to seek to manipulate their intake, given particular incentives, some will do so.

This research has brought to light a number of issues relating to the admissions process which suggest legislative changes are needed if some groups of pupils are not to be discriminated against. One concern is that the admissions process is unduly complex. Admissions criteria for community and voluntary controlled schools are, in the main, clear, objective and relatively simple for parents/carers to understand. With voluntary aided schools there can be a large number of criteria relating to religion and religious practice, creating difficulties for parents/carers and allowing scope for discretion; there is a case for a simplified procedure for determining religion and religious practice (Allen and West, 2009). 
A significant proportion of academies and foundation schools were found to select a proportion of children on the basis of aptitude/ability in a subject area. The goal of this type of selection is likely to vary. However, if the aim is to secure a more academically balanced intake, to widen access to particular schools and create greater social equity, 'fair banding' across a wide area on the basis of the range of ability of children in that area or a form of random allocation across the area are likely to be more effective. Moreover, as noted by Coldron et al. (2009) 'there are strong arguments to suggest that selection by aptitude is likely to be socially selective by default even without active covert selection by schools' (p. 260).

There is a concern about the nature of the SIFs which may result in some parents being disadvantaged during the admissions process and raises questions about 'fairness'. Questions were not necessarily related to the admissions criteria and in some cases similar to those not permitted and could be used to 'select out' particular children. The SIFs which parents/carers needed to fill in could be lengthy. This may disadvantage some parents, particularly those who are unfamiliar with the secondary school application process, those from families with lower levels of education and those for whom English is not their first language. This in turn could deter such parents from submitting an application.

According to the DCSF: 'The admissions system can appear very complex to some parents' (2007, para 1.65). However, our research suggests that the system may not appear complex but be complex and especially for parents/carers who are not educated to a high level. Choice advisers may assist with the admissions process, but they do not address the inherent complexity and lack of clarity. Amongst changes proposed by the Office of the Schools Adjudicator (2008) were for model supplementary information forms to be drawn up and standard wording for admissions criteria published.

More fundamentally, schools that are responsible for their own admissions may exert discretion when making decisions about which pupils should be offered places in the event of the school being oversubscribed. Particular concerns have been raised about admissions to faith schools (Allen and West, 2009; Walford, 2008) and to allay concerns and ensure procedural fairness there is a strong case for either the local authority or independent body taking responsibility for the allocation process. More generally in relation to fairness, it has been argued that in the long term there should be 'fair banding' by ability across a wide area for secondary schools in order to achieve a fair spread of ability across all secondary schools (Tough and Brooks, 2007). 
In theory, it might be argued that LAs could be proactive given that under the 2006 Education and Inspections Act, they have a duty to ensure 'fair access to educational opportunity' (Part 1, s 1 (1) (b)). It would seem that admissions criteria and practices operated by some secondary schools, in the main those with responsibility for admissions, are likely to result in some more advantaged parents gaining a place for their child at their preferred secondary school; this is likely to be the case with partial selection on the basis of ability or aptitude suggesting that fair access to educational opportunity has not yet been achieved.

Finally, key questions still remain in relation to the link between admissions criteria and practices and school composition. Until data are made available enabling the patterns of application and reasons for application to those schools to be matched to offers, it will be unclear whether school autonomy in relation to school admissions may be a factor in determining which pupils apply to which schools and which are offered places.

\section{References}

Allen, R. and West, A. (2009) Religious Schools in London: School Admissions, Religious Composition and Selectivity, Oxford Review of Education, 35, 4, 471-494.

Audit Commission (1996) Trading Places: The supply and allocation of school places. London: The Audit Commission.

Chitty, C. (2004) Education Policy in Britain, London: Palgrave Macmillan.

Coldron, J., Tanner, E., Finch, S., Shipton, L., Wolstenholme, C., Willis, B., Demack, S. and Stiell, B. (2008) Secondary school admissions, London: DCSF.

Coldron, J., Willis, B. and Wolstenholme, C. (2009) Selection by attainment and aptitude in English secondary schools, British Journal of Educational Studies, 57, 3, 245-264.

Department for Children, Schools and Families (2007) Schools and pupils in England 2007 (Final), London: DCSF. http://www.dcsf.gov.uk/rsgateway/DB/SFR/s000744/UPDATEDSFR30_2007.pdf 
Department for Children, Schools and Families (2008a) Education and training statistics for the United Kingdom 2008 (Internet only), London: DCSF.

http://www.dcsf.gov.uk/rsgateway/DB/VOL/v000823/V01-2008.pdf

Department for Children, Schools and Families (2008b) Compliance with the School Admissions Code, London: DCSF.

Department for Children, Schools and Families (2009) School Admissions Code, London: DCSF.

Department for Education and Employment (1999) Code of Practice on School Admissions. London: DfES.

Department of Education and Science (1988) Statistics of Education School Leavers GCSE and GCE 1988, London: DES.

Department for Education and Skills (2003) Code of Practice on School Admissions, London: DfES.

Department for Education and Skills (2007) School Admissions Code. London: DfES. http://www.dcsf.gov.uk/sacode/downloads/DfES\%20Schools\%20text\%20final.pdf

Education (Admission of Looked After Children) (England) Regulations 2006 SI 2006/128, http://www.opsi.gov.uk/si/si2006/20060128.htm

Education and Inspections Act 2006

http://www.opsi.gov.uk/Acts/acts2006/ukpga_20060040_en_1

Floud, J. et al. (1956) Social Class and Educational Opportunity, London: Heinemann.

Gewirtz, S., Ball, S. J. and Bowe, R. (1995) Markets, Choice and Equity in Education, Buckingham: Open University Press.

Gordon, P., Aldrich, R. and Dean, D. (1991) Education and Policy in England in the Twentieth Century, London: The Woburn Press. 
HC (2005) SEN, col. 949W, 18 Oct 2005, London: Hansard.

http://www.publications.parliament.uk/pa/cm200506/cmhansrd/vo051018/text/51018w34.htm

HC (2009) Pupils: Disadvantaged and Special Educational Needs, col. 236W 30, Jun 2009, London: Hansard.

http://www.publications.parliament.uk/pa/cm200809/cmhansrd/cm090630/text/90630w0026.htm\#0 $\underline{9063092000034}$

HC Committee on Education and Skills (2004) Fourth Report of the Education and Skills Committee 2003/04 Secondary Education: School Admissions HC 58-1. London: Stationery Office.

Inner London Education Authority (1985) Improving Primary Schools: Report of the Committee on Primary Education, London: ILEA.

Le Grand, J. and Bartlett, W. (eds.) (1993) Quasi-Markets and Social Policy, London: Macmillan.

Office of the Schools Adjudicator (2008) Annual Report: September 2007 to August 2008, Darlington: Office of the Schools Adjudicator.

Pennell, H., West, A. and Hind, A. (2006) Secondary school admissions in London, Clare Market Papers 19, Centre for Educational Research, London: LSE.

School Admissions (Admission Arrangements) (England) Regulations 2008. SI 2008/3089. http://www.opsi.gov.uk/si/si2008/pdf/uksi_20083089_en.pdf

Simon, B. (1991) Education and the Social Order, London: Lawrence and Wishart.

Tough, S. and Brooks, R. (2007) School admissions: Fair choice for parents and pupils, London: Institute for Public Policy Research.

Walford, G. (2008) Faith-based schools in England after ten years of Tony Blair, Oxford Review of Education, 34, 6, 689-699.

West, A. (2005) 'Banding' and secondary school admissions: 1972-2004, British Journal of Educational Studies, 53, 1, 19-33. 
West, A. (2006) School choice, equity and social justice: The case for more control, British Journal of Educational Studies, 54, 1, 15-33.

West, A., Barham, E. and Hind, A. (2009) Secondary school admissions in England: Policy and practice, London, Research and Information on State Education Trust.

West, A., Hind, A. and Pennell, H. (2004) School admissions and 'selection' in comprehensive schools: Policy and practice, Oxford Review of Education, 30, 3, 347-369.

West, A., Pennell, H., Hind, A. (2009) Quasi-regulation and principal-agent relationships: Secondary school admissions in London, England, Educational Management, Administration and Leadership, 37, 6, 784-805.

West, A., Pennell, H. and Noden, P. (1998) School admissions: increasing equity, accountability and transparency, British Journal of Educational Studies, 46, 2, 188-200. 


\section{Acknowledgements}

The research reported here was commissioned by the Research and Information on State Education (RISE) Trust with funding from the Esmée Fairbairn Foundation. Thanks are due to all those who provided information, in particular the LAs and schools concerned. We would like to thank Matthew West for research assistance, John Wilkes for administrative support and two anonymous reviewers. 


\section{Endnotes}

${ }^{1}$ The resulting structure was in practice a bipartite system with grammar schools and secondary modern schools; in 1958 fewer than 4 per cent of the secondary group attended technical schools (Chitty, 2004).

${ }^{2}$ There are 164 grammar schools in England; they are socially selective with only $2 \%$ eligible for free school meals compared with $13.4 \%$ in maintained secondary schools (HC 2009).

${ }^{3}$ If a school is undersubscribed then all applications must be offered a place, unless the child does not meet minimum academic standards set for entry to a grammar school (see DfES, 2007).

${ }^{4}$ A new School Admissions Code came into force in February 2009 (DCSF, 2009). This, like the earlier Code, has mandatory requirements as well as guidance.

${ }^{5}$ From 2010/2011 no new selection in design and technology or information technology is permitted.

${ }^{6}$ In a minority of cases criteria for September 2002 were used.

${ }^{7}$ The analysis also covered the admissions process for parents/carers living in the City of London. Although there were no secondary schools, for September 2008 entry parents/carers used the Tower Hamlets common application form to express preferences for schools for their children, with this LA also administering their applications. Children living in this area had priority of admission to City of London Academy in Southwark. ${ }^{8}$ In England in January 2008 according to DCSF figures (DCSF, 2008b) there were 3140 secondary schools (excluding middle deemed secondary); our figure was 3134 the difference being due to school closures. Our sample of academies was higher than in January 2008 (94 compared with 83) and the number of city technology colleges lower (3 compared with 5). Schools were classified according to their status on 1 September 2008.

${ }^{9}$ In $2008,91 \%$ of schools mentioned special educational needs elsewhere in the brochure, not specifically with their admissions criteria.

${ }^{10}$ The mean number of bands was 5 (range 3 to 15 ).

${ }^{11}$ Southwark stopped banding in 1993 but has since reintroduced it (see West, 2005).

${ }^{12}$ Previous research (West et al., 2004) examined whether designated specialist schools were more likely than non-specialist schools to be selecting pupils by ability/aptitude in a subject area. However, given the increase in the proportion of schools with specialist status (in September 2008, 85\% of secondary schools were specialist) we have not examined this issue in this report. 